\title{
Morphometric analysis of the sella turcica in Turkish individuals with different dentofacial skeletal patterns
}

\author{
G. Magat, S. Ozcan Sener \\ Department of Oral and Maxillofacial Radiology, Dentistry Faculty, Necmettin Erbakan University, Konya, Turkey \\ [Received: 15 November 2017; Accepted: 5 February 2018]
}

Background: The aim of this study was to evaluate the morphometric analysis of sella turcica in a Turkish population according to gender, age, and dentofacial skeletal type and to investigate the prevalence of sella turcica shapes in different dentofacial skeletal types.

Materials and methods: The lateral cephalometric radiographs of 362 patients (145 males, 217 females) were included and grouped by age, gender, and dentofacial skeletal patterns. Linear dimensions of sella turcica, which include the length, height, and diameter, were measured, and the shapes of sella turcica were evaluated.

Results: The anatomical variants of the sella turcica in this study were normal morphology (39.0\%), followed by pyramidal shape (15.5\%), double contour of floor (14.6\%), oblique anterior wall (14.4\%), irregular dorsum sella (8.6\%), and sella turcica bridge (8.0\%). Significant differences were found between sella turcica shapes and dentofacial skeletal types $(p<0.01)$. Females had greater diameter size of sella turcica than males $(p<0.01)$. In addition, the subjects in the 15-21 age group had larger sella turcica depths and diameters than the subjects in the 9-14 age group ( $p<0.05$ and $p<0.01$, respectively). However, no significant differences were found between age groups in terms of sella turcica lengths $(p>0.05)$.

Conclusions: Results from this study showed that the sample had a higher rate of morphological variation (39\% normal, 61\% other types) in comparison with other populations or ethnic groups. The class III patients had more irregularity (notching) types in the posterior part of the dorsum sella and fewer oblique anterior wall types than the others. Linear dimensions and morphological types of sella turcica in this study can be used as reference for additional investigators, such as radiologists, orthodontists, maxillofacial surgeons, and neurosurgeons, to interpret and plan surgical procedures involving the sellar region. (Folia Morphol 2018; 77, 3: 543-550)

Key words: sella turcica, skeletal, gender, age, lateral cephalometric 


\section{INTRODUCTION}

Sella turcica is situated in the mid-cranial region and lies on the intracranial surface of the sphenoid body. It has a complex anatomical structure and relationship with various anatomical entities such as the pituitary gland, internal carotid artery, and cranial nerves [34, 42]. Two anterior and two posterior clinoid processes are located over the pituitary fossa. The anterior clinoid process is part of the lesser wing of the sphenoid bone, and the posterior clinoid process stands for terminations of the dorsum sellae [45]. The size and shape of clinoid processes may vary: they can be short and blunt or protrude above the pituitary fossa and are sometimes connected. Remodelling of tuberculum sellae and the posterior border of sella turcica continued up to 16-18 years of age [26]. The floor of the sella turcica is the pituitary fossa with the pituitary gland $[20,41]$. Any abnormal or pathologic status in the gland could cause a variation of the sella turcica shape and the glandular hormones secretion [4].

Clinicians should provide a basis for identifying and effectively investigating changes, even before the onset of symptoms of pituitary or craniofacial syndromes, which may reflect pathologic conditions, the variability of normal radiographic anatomy, and sella turcica. These changes can also occur in some syndromes and craniofacial abnormalities that affect the craniofacial region such as primary hypopituitarism, Williams syndrome, growth hormone deficiency, Cushing's syndrome, lumbosacral myelomeningocele, the presence of intrasellar adenomas, empty sella syndrome, and Rathke's cleft cysts and aneurysms $[5,8,15,31,43]$. By means of magnetic resonance imaging (MRI), Baleriaux et al. [9] concluded that macroadenomas, meningiomas, craniopharyngiomas, and cysts are more probable causes of deformation of the neighbouring bony structures.

In addition, the sella turcica is a vital anatomical landmark in lateral cephalometric analysis for the assessment of cranial morphology and jaw relations, which may affect orthodontic diagnosis and management $[4,34]$. In the recent literature, whether or not the morphology of sella turcica is the correlation of dentofacial skeletal types is still under investigation [40]. However, the distinction between different skeletal types is sometimes not possible because the lateral cephalometric analysis might be insufficient for evaluation of marginal intermaxillary positions [40]. Therefore, knowing about the relation between the sella turcica shape and size and the dentofacial skeletal types can be beneficial for providing an accurate decision for the management plan. Moreover, morphometric information about the sella turcica is essential for neurosurgeons to choose the most suitable surgical procedure to prevent damage to structures in relation to the pituitary [44].

To assess whether the sellar region has a normal or unusual appearance, the normal morphology of the sella turcica should be studied. The shape and sizes of sella turcica may alter greatly from person to person, and the knowledge of normal standards for clinicians will help to discriminate any abnormality in this area. Thus, the purposes of this study were (1) to construct a database of normal linear measurements by performing measurements of sella turcica length, depth, and diameter in different genders and different age groups representing the adolescence and early adulthood categories; (2) to examine age- and sex-related differences in sella turcica measurements and shapes and to show whether these parameters are trending significantly; (3) to compare the sella turcica measurements and shapes in the Turkish population with the measurements published in the literature in other countries and ethnic groups; and (4) to suggest ideas for future research on this topic.

\section{MATERIALS AND METHODS}

This retrospective study was conducted on the lateral cephalometric radiographs of 362 patients between 9 and 21 years of age (145 males, 217 females). The radiographs were taken from our Radiology Department archives. This retrospective study was reviewed and approved by the Ethics Committee of Dentistry Faculty of Necmettin Erbakan University, Konya, Turkey.

The individuals with cleft lip, cleft palate, distinct craniofacial syndromes or anomalies, severe skeletal disorders in the vertical dimension, systemic hormonal imbalance, different amounts of calcium intake, or other systemic diseases were excluded from this study. High-quality lateral cephalometric radiographs were selected and then stored with patient details incorporated. The lateral cephalometric radiographs were obtained by the Morita Veraviewepocs 3D R100-P machine (J Morita MFG Corp., Kyoto, Japan) using a standard technique.

The radiographs were grouped according to skeletal classification, gender, and age groups, and they were classified into two age groups of 9-14 
Table 1. Distribution of sample according to gender, age, and skeletal class and $p$ values

\begin{tabular}{|c|c|c|c|c|c|}
\hline \multirow[t]{2}{*}{ Skeletal class } & \multicolumn{2}{|c|}{ Females } & \multicolumn{2}{|c|}{ Males } & \multirow[t]{2}{*}{ Total } \\
\hline & 9-14 years & 15-21 years & 9-14 years & $15-21$ years & \\
\hline Class I & 49 & 32 & 37 & 28 & 146 \\
\hline Class II & 44 & 32 & 21 & 17 & 114 \\
\hline Class III & 39 & 21 & 25 & 17 & 102 \\
\hline Total & 132 & 85 & 83 & 62 & 362 \\
\hline
\end{tabular}

years and 15-21 years. Table 1 shows the sample distribution according to skeletal classes, genders, and age groups. Based on the ANB angle, the individuals were divided into three groups according to the sagittal skeletal dentofacial skeletal pattern: class I $\left(\right.$ ANB; $\left.0-4^{\circ}\right)$, class II $\left(A N B ;>4^{\circ}\right)$, and class III (ANB; < $0^{\circ}$ ) [4].

The linear measurements of length, depth, and diameter were made using the methods described by Silverman [36] and Kisling [18]. The sella turcica length was determined as the distance between the tip of tuberculum sellae and dorsum sellae. The height was evaluated as the perpendicular distance from the line drawn between tuberculum sellae and dorsum sellae to the floor of the sella. The diameter of sella turcica is the anteroposterior distance between the most superior point of tuberculum sellae and the deepest point on the posterior wall of the fossa (Fig. 1). The shapes of the sella turcica were classified based on descriptions by Axelsson et al. [8]. They reported the six morphological variations, including the normal shape (Fig. 2).

Radiologic evaluations were performed by a dento-maxillofacial radiologist (G.M.) with 7 years of experience. The intra-observer agreement was performed by reassessing the greater part of the images twice, with a 4-week interval between viewings.

\section{Statistical analysis}

SPSS statistical software version 21.0 (SPSS, Chicago, IL, USA) was used for statistical calculations. The means, minimum, maximum, and standard deviations were calculated and analysed as descriptive statistics. For the statistical analysis, Kolmogorov-Smirnov, Kruskal-Wallis, and $\chi^{2}$ were used. The intra-observer agreements were assessed by calculating Cronbach's alpha coefficients and kappa values.

\section{RESULTS}

Cronbach's alpha and kappa values for intra-observer reliability were $0.91,0.89,0.92$, and 0.94 , for type, length, height, and diameter of sella turcica,

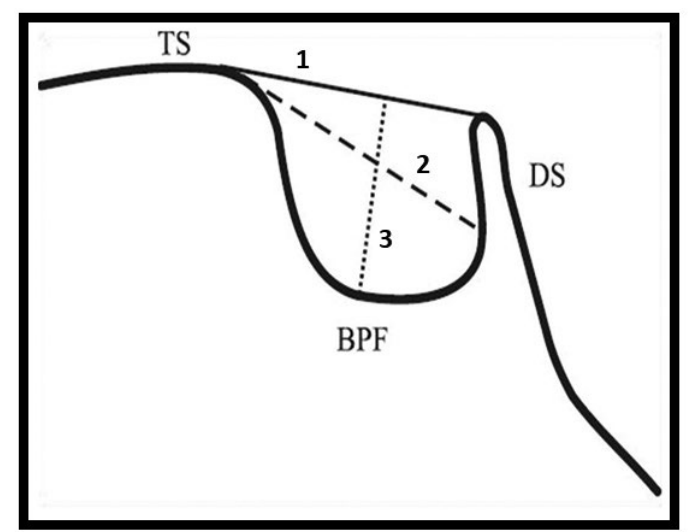

Figure 1. The sella turcica length (1), diameter (2) and height (3); TS - tuberculum sella; DS — dorsum sella; BPF — base of pituitary fossa $[18,36]$.

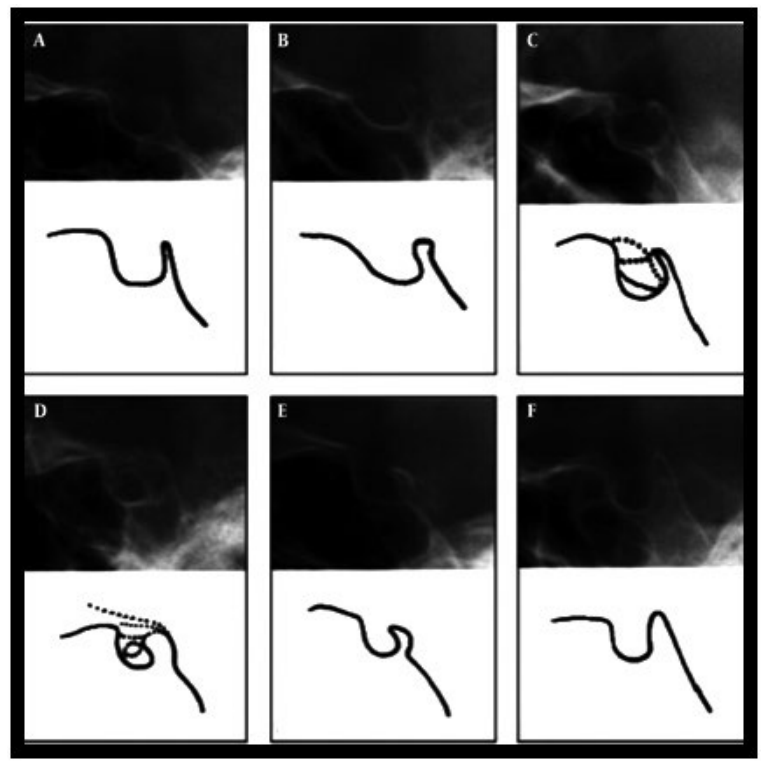

Figure 2. The illustrations of sella turcica shapes according to Axelsson et al. (2004) [8]. A. Normal sella turcica; B. Oblique anterior wall; C. Double contour of sellar floor; D. Sella turcica bridge; $\mathbf{E}$. Irregularity (notching) in the posterior part of the dorsum sella; F. Pyramidal shape of dorsum sella.

respectively, providing good reproducibility for each parameter.

The rates of anatomical variants of the sella turcica in the current study are normal morphology (39.0\%), 
Table 2. The distribution of shape of sella turcica according to skeletal classification and $p$ value between shape of sella turcica and skeletal classification; ${ }^{*} \mathrm{p}<0.01\left(0.000^{*}\right)$

\begin{tabular}{lcccc}
\hline Shape of sella tunica & \multicolumn{3}{c}{ Skeletal classification } & Total \\
\cline { 2 - 4 } & $\mathbf{1}$ & $\mathbf{2}$ & $\mathbf{3}$ & \\
\hline Normal & $54(14.90 \%)$ & $48(13.30 \%)$ & $39(10.80 \%)$ & $14(39.00 \%)$ \\
Oblique anterior wall & $29(8.0 \%)$ & $15(4.1 \%)$ & $8(2.2 \%)$ & $52(14.4 \%)$ \\
Double contour of sella floor & $22(6.1 \%)$ & $20(5.5 \%)$ & $11(3.0 \%)$ & $53(14.6 \%)$ \\
Sella tunica bridge & $13(3.6 \%)$ & $7(1.9 \%)$ & $9(2.5 \%)$ & $29(8.0 \%)$ \\
Irregularity (notching) in the posterior & $4(1.1 \%)$ & $4(1.1 \%)$ & $23(6.4 \%)$ & $31(8.6 \%)$ \\
part of the dorsum sella & & & & \\
Pyramidal shape of the dorsum sella & $24(6.6 \%)$ & $20(5.5 \%)$ & $12(3.3 \%)$ & $56(15.5 \%)$ \\
Total & $146(40.3 \%)$ & $114(31.5 \%)$ & $102(28.2 \%)$ & $362(100.0 \%)$ \\
\hline
\end{tabular}

Table 3. The linear measurement of sella turcica according to shapes of sella tunica and $p$ value between measurements and shapes of sella turcica; ${ }^{*} p<0.01$

\begin{tabular}{lccc}
\hline Shape of sella tunica & \multicolumn{2}{c}{ Linear measurements (mean \pm standard deviation) } \\
\cline { 2 - 4 } & Sella length & Sella height & Sella diameter \\
\hline Normal & $8.11 \pm 1.43$ & $7.62 \pm 1.36$ & $10.82 \pm 1.63$ \\
Oblique anterior wall & $8.26 \pm 1.57$ & $7.52 \pm 1.23$ & $11.24 \pm 1.70$ \\
Double contour of sella floor & $8.01 \pm 1.70$ & $7.60 \pm 1.31$ & $10.84 \pm 1.60$ \\
Sella tunica bridge & $7.79 \pm 2.03$ & $7.83 \pm 1.13$ & $11.34 \pm 1.34$ \\
Irregularity (notching) in the posterior part & $7.11 \pm 1.91$ & $8.35 \pm 1.05$ & $11.26 \pm 1.75$ \\
of the dorsum sella & & & $11.38 \pm 1.69$ \\
Pyramidal shape of the dorsum sella & $8.41 \pm 1.96$ & $8.38 \pm 1.64$ & 0.277 \\
$P$ & 0.072 & $0.000^{*}$ & \\
\hline
\end{tabular}

followed by pyramidal shape (15.5\%), double contour of floor (14.6\%), and oblique anterior wall (14.4\%). The irregular dorsum sella and sella turcica bridge were observed in $8.6 \%$ and $8.0 \%$, respectively. The leastseen sella turcica shape was the sella bridge (8.0\%), and the most common type was the normal shape (39.0\%) (Table 2). Significant differences were found between sella turcica shapes and facial skeletal classifications irrespective of gender and age $(p<0.01)$ (Table 2). The class III patients had more irregularity (notching) in the posterior part of the dorsum sella types than the others, whereas the patients had fewer oblique anterior wall types than the others. $\mathrm{A} \chi^{2}$ test revealed that no significant differences were recorded between the sella turcica shapes and gender and the age group ( $p>0.05$ ). In addition, it was found that the sella height was statistically differed according to the shapes of sella turcica irrespective of gender and age $(p<0.01)$ (Table 3 ). The sella height was higher in subjects with pyramidal shape of the dorsum sella.

The linear dimensions of the sella turcica are shown in Table 4 according to facial skeletal classifi- cation. There were no statistical differences between the dentofacial skeletal patterns and all the sella turcica linear measurements ( $p>0.05$ ) (Table 4). No significant differences were found between females and males in terms of sella turcica length and height. However, females had a greater diameter size of sella turcica than males ( $<<0.01$ ) (Table 5). In addition, it was observed that the subjects in the 15-21 age group had larger sella turcica heights and diameters than the subjects in the 9-14 age group ( $p<0.05$ and $p<0.01$, respectively) (Table 6). However, there were no significant differences between age groups in terms of sella turcica lengths $(p>0.05)$ (Table 6).

\section{DISCUSSION}

This retrospective study described the shapes and sizes of the sella turcica on lateral cephalometric radiographs in Turkish subjects with different dentofacial skeletal types. Hence, the sizes and shapes of the sella turcica were determined and compared with the literature.

The shape variants in the sella turcica have been described by various researchers [11, 22, 40]. One 
Table 4. The mean and standard deviation (SD) values of linear measurements of sella turcica and $p$ value between the linear measurements and skeletal classifications

\begin{tabular}{|c|c|c|c|c|c|}
\hline & Skeletal classification & $\mathbf{N}$ & Mean & SD & $\mathbf{P}$ \\
\hline \multirow[t]{3}{*}{ Sella length [mm] } & Class I & 146 & 8.02 & 1.69 & \\
\hline & Class II & 114 & 8.08 & 1.76 & 0.872 \\
\hline & Class III & 102 & 8.06 & 1.88 & \\
\hline \multirow[t]{3}{*}{ Sella depth [mm] } & Class I & 146 & 7.74 & 1.32 & \\
\hline & Class II & 114 & 7.55 & 1.41 & 0.433 \\
\hline & Class III & 102 & 7.55 & 1.33 & \\
\hline \multirow[t]{3}{*}{ Sella diameter [mm] } & Class I & 146 & 11.16 & 1.62 & \\
\hline & Class II & 114 & 10.83 & 1.57 & 0.296 \\
\hline & Class III & 102 & 11.11 & 1.73 & \\
\hline
\end{tabular}

Table 5. The mean and standard deviation (SD) linear measurement of sella turcica according to gender and $p$ value between the linear measurement of sella turcica and gender; ${ }^{*} p<0.01$

\begin{tabular}{lccccc}
\hline & Gender & $\mathbf{n}$ & Mean & SD & P \\
\hline Sella length $[\mathrm{mm}]$ & Female & 180 & 8.10 & 1.82 & 0.454 \\
& Male & 113 & 7.98 & 1.69 & \\
Sella depth $[\mathrm{mm}]$ & Female & 180 & 7.71 & 1.34 & 0.138 \\
& Male & 113 & 7.51 & 1.37 & \\
Sella diameter $[\mathrm{mm}]$ & Female & 180 & 11.22 & 1.65 & $0.004^{*}$ \\
& Male & 113 & 10.78 & 1.58 & \\
\hline
\end{tabular}

Table 6. The mean and standard deviation (SD) linear measurements of sella turcica and $p$ value between the linear measurements and age groups; ${ }^{*} p<0.01$

\begin{tabular}{lccccc}
\hline & Age group [years] & N & Mean & SD & P \\
\hline Sella length $[\mathrm{mm}]$ & $9-14$ & 215 & 8.10 & 1.73 & 0.300 \\
& $15-19$ & 147 & 7.97 & 1.81 & \\
Sella depth $[\mathrm{mm}]$ & $9-14$ & 215 & 7.41 & 1.34 & $0.000^{*}$ \\
& $15-19$ & 147 & 7.96 & 1.30 & \\
Sella diameter $[\mathrm{mm}]$ & $9-14$ & 215 & 10.73 & 1.58 & $0.000^{*}$ \\
& $15-19$ & 147 & 11.50 & 1.60 & \\
\hline
\end{tabular}

study stated that the massive ossification of the dura mater extended to the dorsum of the sella turcica, and the posterior clinoid processes could alter the morphology of the sellar region [37]. Camp [11] classified the sella turcica as circular, oval, and flattened. He stated that the circular type was the most common type, whereas the flattened type was the least common [11]. Another study [8] described the bridge, oblique anterior wall, double contour of the floor, irregularity of the dorsum sellae, and pyramidal shape of the dorsum sellae as abnormal variations of the sella turcica. They found that two-thirds of the sample had the normal morphological variant. Alkofide [3] noted that there were more anatomic variations in the majority of patients with cleft. Unlike patients with clefts, morphology of sella turcica appears normal in the majority of patients without clefts. In the literature, morphological variations of sella turcica have been reported as more frequent with syndrome patients such as those with Down syndrome [7, 19, 21, 27].

Sathyanarayana et al. [34] reported that $61 \%$ of south Indian subjects with different dentofacial skeletal patterns had normal morphology, and the remaining $39 \%$ had anatomical variants. At least $5 \%$ had an oblique front wall, $5.5 \%$ had a double contour floor, and $5.5 \%$ had a pyramid-like shape of the dorsum sellae. In the studying population, the prevalence of irregularity on the posterior part of the dorsum sellae was reported as $15 \%$, and the bridging of sella turcica was reported as $8 \%$. Unlike the others, Chauhan et al. [13] noted that only $28 \%$ of the cases observed had anatomical variations. Anatomical variations included an oblique anterior 
wall $(23 \%)$, irregular sella (18\%), bridging (17\%), and double contour floor (10\%).

According to our results, the anatomical variations of the sella turcica in this study were normal morphology at $39.0 \%$ with the other morphological variations at $61 \%$. The pyramidal shape was $15.5 \%$, double contour floor was $14.6 \%$, and oblique anterior wall was $14.4 \%$. The irregular dorsum sella and sella turcica bridge were observed in $8.6 \%$ and $8.0 \%$, respectively. The least-seen sella turcica shape was the sella bridge (8.0\%), and the most common type was the normal shape (39.0\%). Class III patients had more irregularity of the dorsum sella types than the others and fewer oblique anterior wall types than the others. However, reported normal morphology of sella turcica in patients with different dentofacial skeletal types was $67 \%$. The remaining $33 \%$ of the cases had variations of sella turcica morphologies [4]. Shah et al. [35] found that the normal morphology was also seen in approximately $66 \%$ of the subjects. Our results are lower than the results of previous studies, which may be due to sample size, ethnicity, and the use of different methodologies.

In addition, the prevalence of sella turcica bridging was reported as ranging from $5.5 \%$ to $22 \%$ [8, 17]. Literature indicated that the presence of sella turcica bridging was associated with craniofacial disorders $[1,10]$. Axelsson et al. [7] stated that $13 \%$ of the patients suffering from Williams syndrome had a sella turcica bridge. The study conducted by Leonardi et al. [23] emphasized that the probability of dental anomalies occurring in later periods was higher in individuals with sella turcica bridges during the development period. Valizadeh et al. [40] stated that the prevalence of sella turcica bridging was $13.3 \%$ in subjects with skeletal class I, $13.3 \%$ in subjects with class II, and $43.3 \%$ in subjects with skeletal class III. In this research, the prevalence of sella turcica bridging was $8.0 \%(3.6 \%, 1.9 \%$, and $2.5 \%$ in subjects with different dentofacial skeletal types, respectively). These results were lower than the studies in the literature.

The measurement of the sella turcica and its morphological types are important because changes in the size and shape of sella turcica may be a sign of a disease or pathology in the pituitary gland. The normal dimensions of sella turcica range from $4 \mathrm{~mm}$ to 16 $\mathrm{mm}$ for length, depth, and diameter $[4,8,14,16,28]$. The discrepancies in those studies may be due to different landmarks representing the same dimensions, different degrees of magnification, or different compositions of the study groups (age, gender, ethnicity, etc.) [4]. In the present study, no significant differences were found for the linear measurements of the three facial skeletal classes, but the mean values were consistent with the literature $[4,12,17,24,25,27,35$, 38-40]. Tetradis and Kantor [39] reported the mean length and depth of sella turcica as $10.9 \pm 1.8 \mathrm{~mm}$ and $7.6 \pm 1.7 \mathrm{~mm}$, respectively. Canigur Bavbek, and Dincer [12] stated the normal length and depth values were $10.90 \pm 1.73 \mathrm{~mm}$ and $8.29 \pm 1.66 \mathrm{~mm}$, respectively. In the present study, the mean length and height for all three classes were $8.22 \pm 1.66 \mathrm{~mm}$ and $7.73 \pm 1.33 \mathrm{~mm}$, respectively, which was consistent with the literature [17, 38-40]. Soakar and Nawale [38] reported the mean diameter of sella turcica as $11.18 \pm 1.34 \mathrm{~mm}$, which is consistent with the mean diameter in all three classes of $11.00 \pm 1.68 \mathrm{~mm}$ found in the present study. Alkofide [4] stated that the skeletal classes with class III individuals had a larger diameter of sella compared to class II and class I individuals. Valizadeh et al. [40] found that class III patients had greater sella turcica length than class II and class I. In addition, the sella turcica depth and diameter were nearly the same in subjects with different dentofacial skeletal patterns. The discrepancies from their results might be different degrees of magnification or different compositions of the study groups (age, gender, ethnicity, etc.).

In this study, no significant differences were found between genders in respect to the size of sella turcica, except for the diameter, which is in accordance with the literature $[4,20,32,35,44]$. Females had a greater diameter size of sella turcica than males $(p<0.01)$ (Table 4). Axelsson et al. [8] reported that there was no difference in depth and anteroposterior diameter, while sella turcica showed a significant difference in respect to length when comparing females and males [41]. In a study conducted with southern Indian subjects, it was stated that the length of the sella turcica in males and females was also different [34]. In a recent study on 509 lateral cephalometric radiographs in a Jordanian population, it was found that all parameters, except for the height, showed significant differences between male and female [2].

The age-related increase in the size of the sella turcica correlated with an increase in the size of the pituitary gland $[6,13,33]$. Remodelling of tuberculum sellae and the posterior border of sella turcica continued up to 16-18 years of age [26]. Hence, we evalu- 
ated the morphology of the sella turcica in subjects aged 9 to 21 years. The sella depths and diameters of the 15-21 age group were consistently larger than the 9-14 age group in the present investigation. This result is consistent with studies by Alkofide et al. [4], Pisaneschi and Kapoor [29], and Preston [30]. Preston [30] stated that sella turcica was growing with age and that this growth in females also occurred at an early age. Choi et al. [14] reported that the length, height, and width of the sella turcica increased up to 25 years of age, but after age 26 , no significant increase was found in sella turcica size. Axelsson et al. [8] concluded that sella turcica height increased with the pubertal spurt, but this situation was invalid for the length.

\section{CONCLUSIONS}

The anatomical structure of sella turcica can be studied effectively on lateral cephalometric radiographs. Results from this study showed that the sample had a higher rate of morphological variation (39\% normal, $61 \%$ other types) in comparison with other populations or ethnic groups. Clinicians must know the normal radiographic anatomy and morphological variations of this area in order to recognise and investigate differences that might reflect pathologic signs. The class III patients had more of the irregularity (notching) in the posterior part of the dorsum sella type and less of the oblique anterior wall type than the others. The sella height was higher in subjects with pyramidal shape of the dorsum sella. Linear dimensions and morphological types of sella turcica in this study can be used as reference for additional investigators such as radiologists, orthodontists, maxillofacial surgeons, and neurosurgeons to interpret and plan surgical procedures involving the sellar region. Moreover, the studies in which internal carotid arteries, sphenoid air sinuses, cavernous sinuses, intracranial portions, and pituitary gland sizes are evaluated as three-dimensional in both genders at different ages may provide clearer information about the morphology and shape of sella turcica.

\section{REFERENCES}

1. Abdel-Kader HM. Sella turcica bridges in orthodontic and orthognathic surgery patients. A retrospective cephalometric study. Aust Orthod J. 2007; 23(1): 30-35, indexed in Pubmed: 17679532.

2. Abu Ghaida JH, Mistareehi AJ, Mustafa AG, et al. The normal dimensions of the sella turcica in Jordanians: a study on lateral cephalograms. Folia Morphol. 2017;
76(1): 1-9, doi: 10.5603/FM.a2016.0038, indexed in Pubmed: 27830892.

3. Alkofide EA. Sella turcica morphology and dimensions in cleft subjects. Cleft Palate Craniofac J. 2008; 45(6): 647-653, doi: 10.1597/07-058.1, indexed in Pubmed: 18956933.

4. Alkofide EA. The shape and size of the sella turcica in skeletal Class I, Class II, and Class III Saudi subjects. Eur J Orthod. 2007; 29(5): 457-463, doi: 10.1093/ejo/cjm049, indexed in Pubmed: 17693429.

5. Ammar A, Al-Sultan A, Al Mulhim F, et al. Empty sella syndrome: does it exist in children? J Neurosurg. 1999; 91(6): 960-963, doi: 10.3171/jns.1999.91.6.0960, indexed in Pubmed: 10584841.

6. Argyropoulou M, Perignon F, Brunelle $F$, et al. Height of normal pituitary gland as a function of age evaluated by magnetic resonance imaging in children. Pediatr Radiol. 1991; 21(4): 247-249, indexed in Pubmed: 1870916.

7. Axelsson S, Storhaug K, Kjaer I. Post-natal size and morphology of the sella turcica in Williams syndrome. Eur J Orthod. 2004; 26(6): 613-621, doi: 10.1093/ejo/26.6.613, indexed in Pubmed: 15650071.

8. Axelsson S, Storhaug K, Kjaer I. Post-natal size and morphology of the sella turcica. Longitudinal cephalometric standards for Norwegians between 6 and 21 years of age. Eur J Orthod. 2004; 26(6): 597-604, doi: 10.1093/ ejo/26.6.597, indexed in Pubmed: 15650069.

9. Baleriaux $D$, Jacquemin C, Lemort M. [Magnetic resonance imaging of the pituitary gland and the sella turcica region. Normal and pathological aspect]. Ann Endocrinol (Paris). 1990; 51(3-4): 173-180, indexed in Pubmed: 2291633.

10. Becktor JP, Einersen S, Kjaer I. A sella turcica bridge in subjects with severe craniofacial deviations. Eur J Orthod. 2000; 22(1): 69-74, indexed in Pubmed: 10721247.

11. Camp JD. Normal and pathological anatomy of the sella turcica as revealed by roentgenograms. Am J Roentgenol. 1924; 12: 143-56.

12. Canigur Bavbek N, Dincer M. Dimensions and morphologic variations of sella turcica in type 1 diabetic patients. Am J Orthod Dentofacial Orthop. 2014; 145(2): 179-187, doi: 10.1016/j.ajodo.2013.10.011, indexed in Pubmed: 24485732.

13. Chauhan P, Kalra S, Mongia $S$, et al. Morphometric analysis of sella turcica in North Indian population: a radiological study. Int J Res Med Sci. 2014; 2(2): 521, doi: 10.5455/2320-6012.ijrms20140529.

14. Choi WJ, Hwang EH, Lee SR. The study of shape and size of normal sella turcica in cephalometric radiographs. Korean J Oral Maxillofacial Radiol. 2001; 31(1): 43-49.

15. Dostálová S, Sonka K, Smahel Z, et al. Cephalometric assessment of cranial abnormalities in patients with acromegaly. J Craniomaxillofac Surg. 2003; 31(2): 80-87, indexed in Pubmed: 12628596.

16. Jones RM, Faqir A, Millett DT, et al. Bridging and dimensions of sella turcica in subjects treated by surgical-orthodontic means or orthodontics only. Angle Orthod. 2005; 75(5): 714-718, doi: 10.1043/0003-3219(2005)75[714:BADOST]2.0.CO;2, indexed in Pubmed: 16279819.

17. Kantor ML, Norton LA. Normal radiographic anatomy and common anomalies seen in cephalometric films. Am J Orthod Dentofacial Orthop. 1987; 91(5): 414-426, indexed in Pubmed: 3554978. 
18. Kisling E. Cranial morphology in Down's syndrome: A comparative roentgenencephalometric study in adult males. Munksgaard. 1966.

19. Kjaer I, Hansen N, Becktor KB, et al. Craniofacial morphology, dentition, and skeletal maturity in four siblings with Seckel syndrome. Cleft Palate Craniofac J. 2001; 38(6): 645-651, doi: 10.1597/1545-1569_2001_038_0645_ cmdasm_2.0.co_2, indexed in Pubmed: 11681999.

20. Konwar SK, Singhla A, Bayan R. Morphological (Length, Depth, and Diameter) Study of Sella Turcica in Different Mandibular Growth Patterns in Indians IJDMS. 2016; 3(3): 1-7.

21. Korayem M, AlKofide E. Size and shape of the sella turcica in subjects with Down syndrome. Orthod Craniofac Res 2015; 18(1): 43-50.

22. Kucia A, Jankowski T, Siewniak M, et al. Sella turcica anomalies on lateral cephalometric radiographs of Polish children. Dentomaxillofac Radiol. 2014; 43(8): 20140165, doi: 10.1259/dmfr.20140165, indexed in Pubmed: 25182120.

23. Leonardi R, Barbato E, Vichi M, et al. A sella turcica bridge in subjects with dental anomalies. Eur J Orthod. 2006; 28(6): 580-585, doi: 10.1093/ejo/cjl032, indexed in Pubmed: 16954179 .

24. Luong HM, Ahn JH, Bollu P, et al. Sella Turcica Variations in Skeletal Class I, Class II, and Class III Adult Subjects: A CBCT Study. J Dent Oral Biol. 2016; 1(3): 1015-1021.

25. Marşan G, Öztaş E. Incidence of bridging and dimensions of sella turcica in Class I and III Turkish adult female patients. World J Orthod. 2009; 10(2): 99-103, indexed in Pubmed: 19582250.

26. Melsen B, Melsen F. The postnatal development of the palatomaxillary region studied on human autopsy material. Am J Orthod. 1982; 82(4): 329-342, indexed in Pubmed: 6961805.

27. Meyer-Marcotty P, Reuther T, Stellzig-Eisenhauer A. Bridging of the sella turcica in skeletal Class III subjects. Eur J Orthod. 2010; 32(2): 148-153, doi: 10.1093/ejo/cjp081, indexed in Pubmed: 19752019.

28. Moffitt AH. Discovery of pathologies by orthodontists on lateral cephalograms. Angle Orthod. 2011; 81(1): 58-63, doi: 10.2319/040510-190.1, indexed in Pubmed: 20936955.

29. Pisaneschi M, Kapoor G. Imaging the sella and parasellar region. Neuroimaging Clin N Am. 2005; 15(1): 203-219, doi: 10.1016/j.nic.2005.02.007, indexed in Pubmed: 15927868.

30. Preston CB. Pituitary fossa size and facial type. Am J Orthod. 1979; 75(3): 259-263, indexed in Pubmed: 285608.

31. Russell BG, Kjaer I. Postnatal structure of the sella turcica in Down syndrome. Am J Med Genet. 1999; 87(2): 183-188, indexed in Pubmed: 10533034.

32. Sakran AM, Khan MA, Altaf FMN, et al. et al.. A morphometric study of the sella turcica: gender effect. Int J Anat Res. 2015; 3(1): 927-934.
33. Sari S, Sari E, Akgun V, et al. Measures of pituitary gland and stalk: from neonate to adolescence. J Pediatr Endocrinol Metab. 2014; 27(11-12): 1071-1076, doi: 10.1515/ jpem-2014-0054, indexed in Pubmed: 25367689.

34. Sathyanarayana HP, Kailasam V, Chitharanjan AB. Sella turcica-Its importance in orthodontics and craniofacial morphology. Dent Res J (Isfahan). 2013; 10(5): 571-575, indexed in Pubmed: 24348611.

35. Shah AM, Bashir U, llyas T. The shape and size of the sella turcica in skeletal Class I, II and III in patients presenting at Islamic International Dental Hospital, Islamabad. PODJ. 2011; 31(1).

36. Silverman FN. Roentgen standards fo-size of the pituitary fossa from infancy through adolescence. Am J Roentgenol Radium Ther Nucl Med. 1957; 78(3): 451-460, indexed in Pubmed: 13458563.

37. Skrzat J, Kozerska M, Wróbel A. Micro-computed tomography study of the abnormal osseous extensions of sella turcica. Folia Morphol. 2014; 73(1): 19-23, doi: 10.5603/ FM.2014.0003, indexed in Pubmed: 24590518.

38. Soaker PC, Nawale S. The comparative study of size of sella turcica in different skeletal types in local population: an in vitro study. Indian J Appl Res. 2014; 4: 160-162.

39. Tetradis S, Kantor ML. Prevalence of skeletal and dental anomalies and normal variants seen in cephalometric and other radiographs of orthodontic patients. Am J Orthod Dentofacial Orthop. 1999; 116(5): 572-577, indexed in Pubmed: 10547519.

40. Valizadeh S, Shahbeig S, Mohseni S, et al. Correlation of shape and size of sella turcica with the type of facial skeletal class in an iranian group. Iran J Radiol. 2015; 12(3): e16059, doi: 10.5812/iranjradiol.12(3)2015.16059, indexed in Pubmed: 26557271.

41. Venieratos D, Anagnostopoulou S, Garidou A. A new morphometric method for the sella turcica and the hypophyseal fossa and its clinical relevance. Folia Morphol. 2005; 64(4): 240-247, indexed in Pubmed: 16425149.

42. Wang J, Wang R, Lu Y, et al. Anatomical analysis on the lateral bone window of the sella turcica: a study on 530 adult dry skull base specimens. Int J Med Sci. 2014; 11(2): 134-141, doi: 10.7150/ijms.7137, indexed in Pubmed: 24465158

43. Weisberg LA, Zimmerman EA, Frantz AG. Diagnosis and evaluation of patients with an enlarged sella turcica. Am J Med. 1976; 61(5): 590-596, indexed in Pubmed: 984063.

44. Yasa Y, Ocak A, Bayrakdar IS, et al. Morphometric analysis of sella turcica using cone beam computed tomography. J Craniofac Surg. 2017; 28(1): e70-e74, doi: 10.1097/ SCS.0000000000003223, indexed in Pubmed: 27922970.

45. Zagga AD, Ahmed H, Tadros AA, et al. Description of the normal variants of the anatomical shapes of the sella turcica using plain radiographs: experience from Sokoto, Northwestern Nigeria. Ann Afr Med. 2008; 7(2): 77-81, indexed in Pubmed: 19143164. 